\title{
Herbivory damage in native Alnus nepalensis and invasive Ageratina adenophora
}

\author{
Sujan Balami ${ }^{1}$ and Lal B Thapa ${ }^{2 *}$ \\ ${ }^{1}$ Department of Botany, Amrit Science Campus, Tribhuvan University, Kathmandu, Nepa \\ ${ }^{2}$ Central Department of Botany, Tribhuvan University, Kirtipur, Kathmandu, Nepal
}

\begin{abstract}
There are numbers of invasive and naturalized alien species in Nepal but studies related to herbivory effects on such species are scarce. An issue of debate is whether invasive alien species get benefited by less herbivory damage in their introduced range. In this study, we investigated the level of herbivory damage in Alnus nepalensis in an area invaded by Ageratina adenophora in Nepal. The damage was compared between invasive $A$. adenophora and native Alnus nepalensis. Results showed that $A$. adenophora experienced lower level of leaf damage by herbivores than that of $A$. nepalensis. This indicated that the invasive $A$. adenophora might have benefited from reduced herbivory damage behind its successful invasion in Nepalese forest. Further studies are needed to confirm whether controlling of herbivores to lessen the damage in native Alnus nepalensis could enhance its competitive ability against Ageratina adenophora in native vegetation of Nepal.
\end{abstract}

Key-words: alien invasion, enemy release hypothesis, herbivory damage, native species.

\section{Introduction}

Enemy release hypothesis (ERH) is commonly accepted mechanism for invasion success of alien species, which is corroborated by different experimental evidences (Agrawal et al. 2005; Vila et al. 2005). ERH predicts that invasive alien species (IAS) are capable of attaining vigorous growth at their introduced range and exhibit an increase in the distribution and abundance due to a decrease in regulation by natural enemies (Keane and Crawley 2002; Liu and Stiling 2006; Roy et al. 2011).

Enemy, in general, represents herbivores of different guilds (insects, nematodes, and microbes). In general, if native and invasive species are distant phylogenetically, the native herbivores (e.g., insects) can hardly switch to the invading species (Bertheau et al. 2010). Consequently, IAS show competitive advancement over native species by release out from natural enemies; i.e. they are benefited, such as in allocation of resources for growth and reproduction than in herbivore defense activities (Blossey and Notzold 1995; Dietz et al. 2004; Lake and Leishman 2004). This strategic trait of IAS affects growth and development of native species (Gorchov and Trisel 2003; Stinson et al. 2006; Hejda et al. 2009).

In the context of Nepal, ecological impacts caused by aggressively invading and naturalized alien species have been documented (e.g. Tiwari et al. 2005; Thapa et al. 2015; Shrestha 2016; Thapa et al. 2016a), but the studies on specific mechanism of alien invasiveness including ERH are untouched. In this regard, it would be interesting to study the damage caused by natural enemies to native and invasive species and explore whether IAS are taking the benefit of less herbivory damage for their rapid growth. Studies on ERH in invasion ecology generally involve comparing IAS with its native congeners regarding their growth and herbivory damage (Agrawal and Kotanen 2003). However, for the purpose to generate a simple idea on ERH, taxonomically different, but co-occurring, native and invasive pairs can also be selected for comparing enemy damage level if there is lack of congeneric member.

In this study we compare the level of herbivory damage between invasive Ageratina adenophora (Spreng.) King $\&$ H. Rob. and native Alnus nepalensis D. Don. Ageratina adenophora (hereafter referred to as Ageratina) of family Asteraceae was introduced in Nepal around 1950s and now it has been naturalized in most parts of the country between 850 and $2200 \mathrm{~m}$ asl (Press et al. 2000; Tiwari et al. 2005). Alnus nepalensis (hereafter referred to as Alnus) of the family Betulaceae was selected as a native species to compare herbivory effect along with Ageratina because both grow on degraded forest patches with varying climatic and soil conditions (Orwa et al. 2009; Tripathi et al. 2011; Thapa et al. 2016b). A hypothesis set in the study was that the native Alnus suffer from high level of herbivory damage than the invasive Ageratina. 


\section{Materials and Methods}

STUDY SITE

The study was conducted in Champadevi Community Forest (elevation range: $1400-2300 \mathrm{~m}$ asl; location: $27^{\circ} 42^{\prime} \mathrm{N}$ and $85^{\circ} 19^{\prime}$ E) at southwest of Kathmandu valley. The community forest is invaded by Ageratina. The forest was highly degraded in the past, but its natural recovery has been achieved after conservation efforts of local people for two decades (Thapa et al. 2016b). A competition between growing Alnus saplings and Ageratina can be observed in field condition.

\section{DAMAGE ASSESSMENT}

The assessment was conducted in August 2016. Leaf damage in both native and invasive species was measured in the form of damage percentage. The damage was categorized into herbivory bites and necrotic spots. A total of 20 individuals of each Ageratina and Alnus were selected from Ageratinainvaded forest patches along a line transect. Distance between the patches was approximately $10 \mathrm{~m}$. Alnus saplings having similar height as Ageratina (height ranges from 0.5 to 1.5 $\mathrm{m}$ ) were selected for the study. Four different branches (one branch from base, two from middle and one from top of each plant) were selected from each individual of Alnus. Total number of leaves and number of damaged leaves were counted. In case of Ageratina, four different ramets were selected randomly from the same patches where Alnus saplings were associated. Afterward, percentage of damaged leaves was calculated.

Percentage leaf damage $=\frac{\text { Total no. of damaged leaves in all branches }}{\text { Total number of leaves in all branches }} \times 100$

The damage was also calculated in terms of percentage leaf area. A total of four damaged leaves from each selected branch were collected $(20$ individuals $\times 4$ branches $\times 4$ leaves $=320$ leaves) for each native and invasive species. Out of 320 leaves, 100 were selected randomly. The leaves were photographed and percentages of leaf area damaged were assessed by using following formula.

Leaf area damage $=\frac{\text { Area of damaged portion of leaf }}{\text { Total area of leaf }} \times 100 \%$

The calculation of leaf area was accompanied with image analyzing software Image J (version 1.49t).

\section{STATISTICAL ANALYSIS}

As the data were not normal, Mann-Whitney-Wilcoxon test was used as a test statistic for analyzing significant difference in damage severity and extent of damage in leaf area. Statistical tests were made by using software R (R Core Team 2015).

\section{Results}

\section{PERCENTAGE OF DAMAGED LEAVES}

Alnus exhibited high percentage of leaf damage than that of Ageratina $(p<0.001)$. In Alnus, leaf damage was 91.00 $\pm 2.62 \%$. Mostly, the damage was by herbivores with characteristics biting signs. In the case of Ageratina, 25.00 $\pm 2.18 \%$ of leaves showed herbivore damage (Figure 1 ). The results revealed that there was about $66 \%$ less leaf damage in Ageratina than in Alnus.

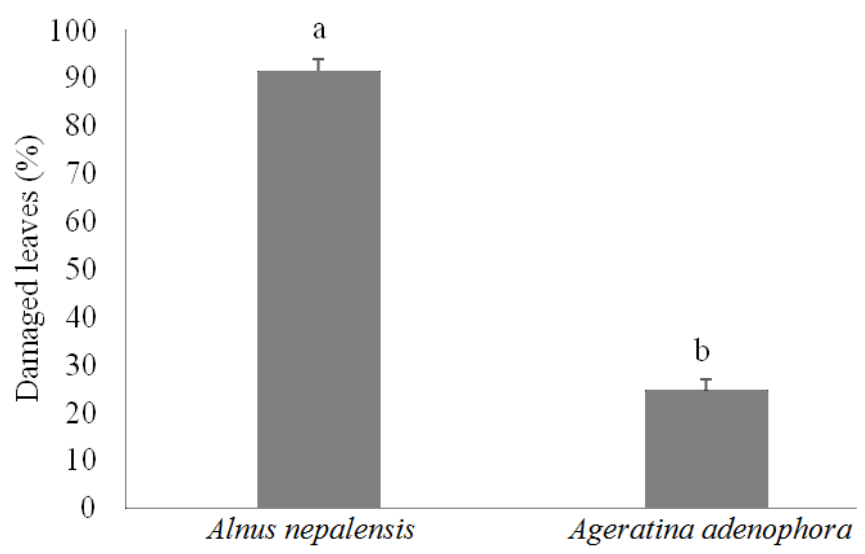

Figure 1. Percentage of damaged leaves in Alnus and Ageratina (the letters above error bar shows significant differences).

\section{PERCENTAGE OF LEAF AREA DAMAGE}

The herbivory damaged leaf area in Alnus was $16.00 \pm$ $1.18 \%$ of total leaf area. In contrast, the damaged leaf area in Ageratina was negligible (i.e., only $0.65 \pm 0.26 \%$; $p<0.001$; Figure 2). On comparing leaf area damage type in Ageratina, the area of necrotic spots was significantly greater $(9.00 \pm$ $0.88 \%)$ than the herbivory bites $(p<0.001$; Figure 3$)$.

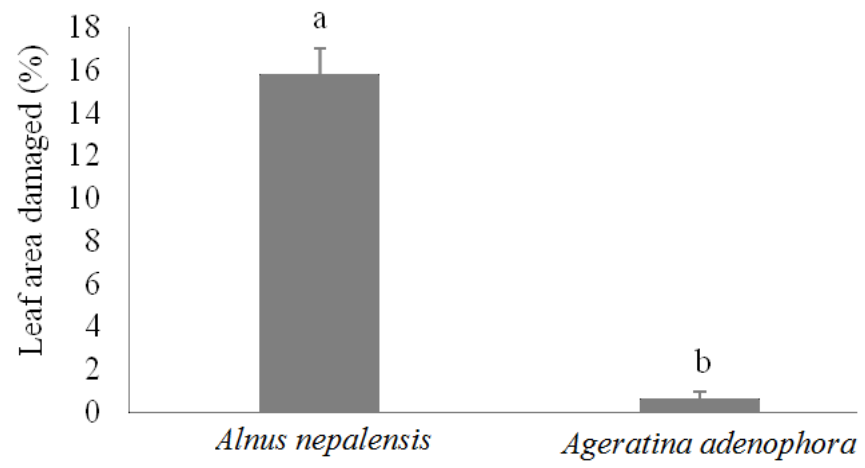

Figure 2. Percentage of leaf area damage in Alnus and Ageratina (the letters above error bar shows significant differences). 


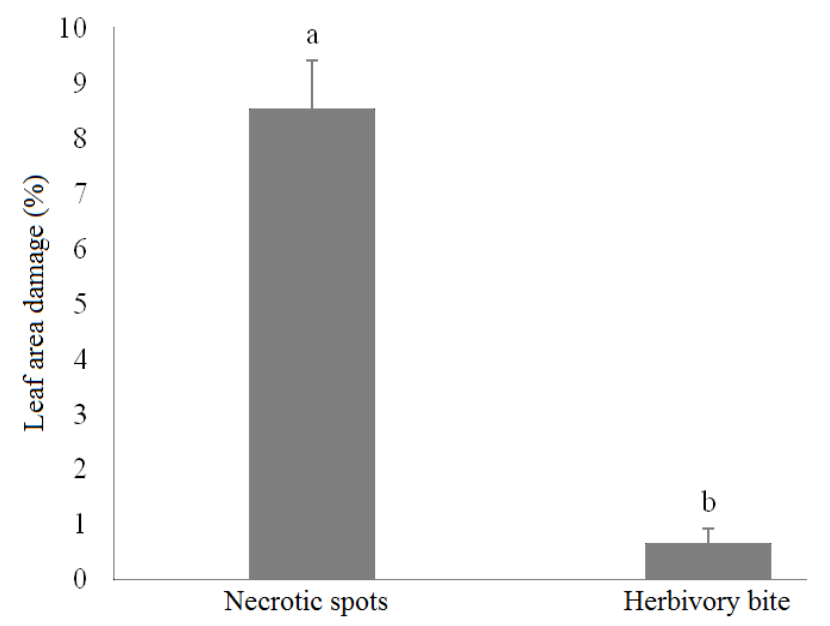

Figure 3. Leaf area damage type in Ageratina (the letters above error bar shows significant differences).

\section{CORRELATION BETWEEN LEAF DAMAGE AND LEAF SIZE}

Correlation analysis showed significant relationship between leaf size and degree of damage in both the native and invasive species. However, the correlation coefficient was much higher in native than in invasive species (Table 1).

Table 1. Spearman rank correlation between leaf size and damaged leaf area.

\begin{tabular}{lcc}
\hline \multicolumn{1}{c}{ Species } & $\begin{array}{c}\text { Correlation } \\
\text { coefficient }\end{array}$ & P value \\
\hline Alnus nepalensis & 0.64 & $<0.001$ \\
Ageratina adenophora & 0.37 & $<0.001$ \\
\hline
\end{tabular}

\section{Discussion}

In accordance with the enemy release hypothesis, Ageratina in this study shows minimal herbivory damage. Contrasting to this, the damage in co-occurring Alnus was the worst. Percentage of damaged leaves was significantly high in Alnus in comparison to Ageratina in terms of number of damaged leaves (Figure 1). Similarly, comparing leaf area damage the difference was also significantly higher in Alnus than in Ageratina (Figure 2).

There are natural enemies of Ageratina in its native range, such as tephritid gall fly, lepidopteran stem borer and curculionid feeding on its shoot tips (Osborne 1924). As a biological control of Ageratina, the gall fly (Procecidochares utilis) has been introduced to other countries but its effect was insignificant, such as in South Africa (Kluge 1991) indicating that the introduced enemies may not effectively damage their host out of their native range. The gall fly was also observed during our field observation but only few numbers of galls were seen developed on Ageratina stem. Although we did not measure the galls developed in the plants, the condition was not likely to cause significant damage in Ageratina. Bites were also observed on leaves of Ageratina which might belong to the fly but they were not severe as compared to the bites of herbivores on Alnus leaves (Figure 1 and 2).

Our results support previous findings; for example, a study conducted by Carpenter and Cappuccino (2005) on herbivory damage between exotic and native plant species in Ottawa, Canada found that the exotics suffered by less herbivores than the native ones. MacKay and Kotanen (2008) observed release of enemy of ragweed (Ambrosia artemisiifolia), where ragweed populations experienced significantly less damage relative to within-population plots. Similarly, test of ERH on Hypericum perforatum showed $58 \%$ of insect damage in native range with only $28 \%$ damage in introduced range (Vila et al. 2005).

There are several other explanations for prolific growth and successful invasion of alien species. Ageratina in their exotic range exhibits vegetative means of reproduction and allelopathy (Wan et al. 2010; Del Fabbro et al. 2014; Thapa et al. 2017). Our study indicates that one of the reasons behind a prolific growth and invasion of Ageratina in Nepal is reduced herbivory also.

Invasion of Ageratina in Nepal dates back to 1950s (Tiwari et al. 2005). It would be interesting to hypothesize that some pests or parasites might have adapted on feeding to Ageratina during this course of long time introduction and establishment in Nepal (about 70 years). We cannot assure that the bites belong to only its natural enemy (Procecidochares utilis), they might also belong to other insects that are co-evolved pests of native plants. We recommend further studies for its confirmation.

In addition, the stronger correlation of leaf size and damage in Alnus and weaker in Ageratina suggest that apart from leaf volatiles and other factors, leaf trait (relatively smaller size) of Ageratina might have aided them to lowered surface area for insects' ovulation and larval attachment. This result creates another opportunity to explore leaf trait and its relation with leaf damage in Ageratina.

Alnus could be a better candidate to compete Ageratina prolific growth regarding habitat preference as both of these species prefer disturbed and varied soil type. Our explanation is that phenological coincidences of native and invasive species are also related with herbivory damage. Usually the months of August-September represent time of active plant growth but at the meantime there is a high herbivore activity during this period. With end of these months, winter starts and all the plants lower their metabolic machinery, consequently there is less chance to recover/compensate the leaf damage/loss during whole winter. Thereby growth and development would be sufficiently low in herbivory-fed Alnus. As the growing season starts Ageratina already makes its way to the soil for their germination (March is the flowering month of Ageratina) where Alnus may still remain defoliated. After germination, 
Ageratina gets well adapted even under Alnus canopy and may develop shade tolerant ability.

In conclusion, all these results imply that native Alnus which co-occur with invasive Ageratina is affected by severe herbivore damage. Native herbivores rarely switch to the invasive Ageratina even for these numbers of years since invasion. All the strategic development for escape, defense tolerance from herbivore is well developed in Ageratina that makes them successful invader in Nepalese forests. Therefore, constrain on Alnus due to herbivory might have hindered its competitive ability against Ageratina prolific growth.

\section{Acknowledgements}

Authors are grateful to Prof. Dr. Mohan Siwakoti, Head of Central Department of Botany and Associate Prof. Dr. Suresh K. Ghimire for giving constructive suggestion to improve the manuscript. Two anonymous reviewers are highly acknowledged for their valuable comments and suggestions.

\section{References}

Agrawal A.A. and Kotanen P.M. 2003. Herbivores and the success of exotic plants: a phylogenetically controlled experiment. Ecology Letters, 6: 712-715.

Agrawal A.A., Kotanen P.M., Mitchell C.E., Power A.G., Godsoe W. and Klironomos J. 2005. Enemy release? An experiment with congeneric plant pairs and diverse above and belowground enemies. Ecology, 86: 2979-2989.

Bertheau C., Brockerhoff E.G., Roux Morabito G., Lieutier F. and Jactel H. 2010. Novel insect tree associations resulting from accidental and intentional biological 'invasions': a meta analysis of effects on insect fitness. Ecology letters, 13: 506-515.

Blossey B. and Notzold R. 1995. Evolution of increased competitive ability in invasive non-indigenous plants: a hypothesis. Journal of Ecology, 83: 887-889.

Del Fabbro C., Güsewell S. and Prati D. 2014. Allelopathic effects of three plant invaders on germination of native species: a field study. Biological Invasions, 16: 1035-1042.

Dietz H., Wirth L.R. and Buschmann H. 2004. Variation in herbivore damage to invasive and native woody plant species in open forest vegetation on Mahé, Seychelles. Biological Invasions, 6: $511-521$

Gorchov D.L. and Trisel D.E. 2003. Competitive effects of the invasive shrub, Lonicera maackii (Rupr.) Herder (Caprifoliaceae), on the growth and survival of native tree seedlings. Plant Ecology, 166: 13-24.

Hejda M., Pyšek P. and Jarošík V. 2009. Impact of invasive plants on the species richness, diversity and composition of invaded communities. Journal of Ecology, 97: 393-403.

Keane R.M. and Crawley M.J. 2002. Exotic plant invasions and the enemy release hypothesis. Trends in Ecology \& Evolution, 17: 164-170.
Kluge R.L. 1991. Biological control of crofton weed, Ageratina adenophora (Asteraceae), in South Africa. Agriculture, Ecosystems \& Environment, 37: 187-191.

Lake J.C. and Leishman M.R. 2004. Invasion success of exotic plants in natural ecosystems: the role of disturbance, plant attributes and freedom from herbivores. Biological Conservation, 117: 215-226.

Liu H. and Stiling P. 2006. Testing the enemy release hypothesis: a review and meta-analysis. Biological Invasions, 8: 1535-1545.

MacKay J. and Kotanen P.M. 2008. Local escape of invasive plant, common ragweed (Ambrosia artemisiifolia L.), from aboveground and belowground enemies in its native area. Journal of Ecology, 96: 1152-1161.

Orwa C., Mutua A., Kindt R., Jamnadass R. and Simons A. 2009. Agroforestree Database: A Tree Species Reference and Selection Guide Version 4.0. World Agroforestry Centre ICRAF, Nairobi, Kenya.

Osborn H.T. 1924. A preliminary study of the pamakani plant (Eupatorium glandulosum H.B.K.) in Mexico with reference to its control in Hawaii. Hawaiian Planters Records, 24: 546-559.

Press J.R., Shrestha K.K. and Sutton D.A. 2000. Annotated Checklist of the Flowering Plants of Nepal. The Natural History Museum, London, UK.

R Core Team 2015. R: A Language and Environment for Statistical Computing. R Foundation for Statistical Computing, Vienna, Austria. [online] URL: http://www.R-project.org/.

Roy H.E., Handley L.J.L., Schönrogge K., Poland R.L. and Purse B.V. 2011. Can the enemy release hypothesis explain the success of invasive alien predators and parasitoids? BioControl, 56: 451-468.

Shrestha B.B. 2016. Invasive alien plant species in Nepal. In: Frontiers of Botany (P.K. Jha, M. Siwakoti and S. Rajbhandari, eds.), pp. 269-284. Central Department of Botany, Tribhuvan University, Kathmandu, Nepal.

Stinson K.A., Campbell S.A., Powell J.R., Wolfe B.E., Callaway R.M., Thelen G.C., Hallett S.G., Prati D. and Klironomos J.N. 2006. Invasive plant suppresses the growth of native tree seedlings by disrupting belowground mutualisms. PLoS Biol, 4: e140. [online] URL: https://doi.org/10.1371/journal.pbio.0040140.

Thapa L.B., Thapa H. and Magar B.G. 2015. Perception, trends and impacts of climate change in Kailali District, Far-West Nepal. International Journal of Environment, 4: 62-76.

Thapa L.B., Kaewchumnong K., Sinkkonen A. and Sridith K. 2016a. Impacts of invasive Chromolaena odorata on species richness, composition and seedling recruitment of Shorea robusta in a tropical Sal forest, Nepal. Songklanakarin Journal of Science \& Technology, 38: 683-689.

Thapa L.B., Kaewchumnong K., Sinkkonen A. and Sridith K. 2016 b. Plant communities and Ageratina adenophora invasion in lower montane vegetation, Central Nepal. International Journal of Ecology \& Development, 31: 35-49. 
Thapa L.B., Kaewchumnong K., Sinkkonen A. and Sridith K. 2017. Plant invasiveness and target plant density: high densities of native Schima wallichii seedlings reduce negative effects of invasive Ageratina adenophora. Weed Research, 57: 72-80.

Tiwari S., Siwakoti M., Adhakari B. and Subedi K. 2005. An Inventory and Assessment of Invasive Alien Plant Species of Nepal. IUCN - The World Conservation Union, Kathmandu, Nepal.

Tripathi R.S., Yadav A.S. and Kushwaha S.P.S. 2011. Biology of Chromolaena odorata, Ageratina adenophora and Ageratina riparia: a review. In: Invasive Alien Plants: An Ecological
Appraisal for the Indian Subcontinent (J.R. Bhatt, J.S. Singh, S.P. Singh, R.S. Tripathi and R.K. Kohli, eds.), pp. 43-56. CAB International Publishing, Wallingford, Oxon, UK.

Vila M., Maron J.L. and Marco L. 2005. Evidence for the enemy release hypothesis in Hypericum perforatum. Oecologia, 142: 474-479.

Wan F., Liu W., Guo J., Qiang S., Li B., Wang J., Yang G., Niu H., Gui F., Huang W. and Jiang Z. 2010. Invasive mechanism and control strategy of Ageratina adenophora (Sprengel). Science China Life Sciences, 53: 1291-1298. 